\title{
Métodos de extração de fósforo e potássio no solo sob sistema plantio direto
}

\author{
Soil phosphorus and potassium extractant in soils under no tillage
}

\author{
Leandro Bortolon ${ }^{\mathrm{I}}$ Jairo André Schlindwein ${ }^{\mathrm{II}}$ Clesio Gianello ${ }^{\mathrm{III}}$
}

\section{RESUMO}

A análise de fósforo e potássio no solo, nos Estados do Rio Grande do Sul e de Santa Catarina, é realizada com a solução de Mehlich-1, e os estudos de seleção de métodos de análise para esses elementos foram feitos apenas para o sistema de cultivo convencional. Neste trabalho, a solução de Mehlich1 foi comparada com a solução de Mehlich-3 e com o método da resina de troca iônica para análise de fósforo e potássio, em solos sob plantio direto, com experimentos de resposta das culturas à adubação fosfatada e potássica instalados no Rio Grande do Sul. As quantidades de fósforo extraídas pelos métodos da resina e Mehlich-3 foram maiores com a solução de Mehlich-1, independentemente da profundidade de amostragem. As quantidades de fósforo extraídas pelos métodos apresentaram alto grau de associação entre si. Para o potássio as quantidades extraídas foram semelhantes entre as metodologias estudadas, com alto grau de associação entre si, independentemente da profundidade de amostragem. As metodologias estudadas são eficientes na extração de fósforo e potássio no solo, em sistema plantio direto. Porém, devido às menores quantidades de $P$ extraído pela solução de Mehlich1 , os erros em laboratório podem ser maiores pela menor amplitude de extração.

Palavras-chave: sistema plantio direto, análise de solo, adubação fosfatada, adubação potássica.

\section{ABSTRACT}

The current soil test method used to evaluate soil phosphorus and potassium available to the plants in soils from Rio Grande do Sul e Santa Catarina state is the Mehlich-1 solution. The soil test methods studies for these nutrients were conducted based on the conventional soil tillage. The aim of this work was to compare the soil phosphorus and potassium amounts extracted by the Mehlich-1 solution and the nutrients amounts extracted by the Mehlich-3 solution, and resin membrane in soils from the Rio Grande do Sul state, under no tillage soil system and nutrients crop response. The phosphorus amounts extracted by the resin method and by the Mehlich-3 solution were higher than that those extracted by the Mehlich1 solution in both of them sampling depth. The correlation coefficients among the phosphorus amounts extracted by the methods were high association degree. The potassium amounts extracted by the methods were similar, and the correlation coefficients among the potassium amounts extracted by the methods were high association degree in all soil sampling depth. The soil testing methods that have studied in this work are efficient for soil phosphorus and potassium extraction in soils under no tillage; however, the lowest soil phosphorus amounts extracted by the Mehlich-1 solution, increase the laboratory errors.

Key words: no tillage systems, soil test methods, phosphate fertilizer, potassium fertilizer.

\section{INTRODUÇÃO}

A metodologia de análise de solo utilizada para avaliação da disponibilidade de fósforo e potássio para as plantas nos Estados do Rio Grande do Sul (RS) e Santa Catarina (SC) é a solução de Mehlich-1. Os estudos realizados nesses Estados com o objetivo de selecionar os métodos de análise de solo para fósforo e potássio foram feitos em casa-de-vegetação, com amostras de solo deformadas, representando o sistema convencional de cultivo (ANGHINONI \& BOHNEN, 1974; MIOLA et al., 1999; BISSANI et al., 2002; BORTOLON \& GIANELLO, 2006).

\footnotetext{
'Programa de Pós-graduação em Ciência do Solo, Universidade Federal do Rio Grande do Sul (UFRGS). Av. Bento Gonçalves, 7712, 91540-000, Porto Alegre, RS, Brasil. E-mail: leandro.bortolon@ufrgs.br. Autor para correspondência.

"Faculdade de Agronomia, Universidade Federal de Rondônia (UNIR), Rolim de Moura, RO, Brasil.

"IIDepartamento de Solos, UFRGS, Porto Alegre, RS, Brasil
} 
Com a adoção do sistema plantio direto (SPD), que atinge atualmente mais de $60 \%$ da área cultivada no RS, surgiram questionamentos sobre a validade de uso dessa metodologia para esse sistema. Uma das principais diferenças entre o sistema convencional de cultivo e o sistema plantio direto é que neste ocorre concentração superficial e subsuperficial de fósforo, potássio, matéria orgânica e outros nutrientes, decorrente das adubações e da reciclagem de nutrientes (SCHLINDWEIN \& ANGHINONI, 2000; ANGHINONI, 2007). Além disto, a retirada de amostras de solo da camada $0-10 \mathrm{~cm}$ de profundidade, com maior concentração em fósforo e potássio, proporciona um valor maior no resultado desses nutrientes da análise do solo, sem que necessariamente ocorra um aumento de rendimento das culturas, tal como observado por SCHLINDWEIN \& ANGHINONI(2000).

No RS e em SC, é crescente o número de pesquisadores que defendem o uso de outros métodos em substituição ao Mehlich 1 para avaliar a disponibilidade de fósforo às plantas. Isso decorre, em parte, devido à baixa previsibilidade da necessidade de adubação fosfatada em solos que recebem fosfatos naturais e também devido às baixas quantidades de fósforo extraído em solos de textura argilosa, o que determina faixas de interpretação de teores de fósforo condicionadas à classificação textural dos solos (RHEINHEIMER et al., 2008). Dentre os métodos alternativos ao Mehlich-1, estão o Mehlich-3 e a resina de troca iônica em membrana, os quais foram testados em outras condições por diversos autores (MIOLA et al., 1999; BISSANI et al., 2002; BORTOLON \& GIANELLO, 2006; BORTOLON \& GIANELLO, 2008; SCHLINDWEIN \& GIANELLO, 2008).

O objetivo do presente trabalho foi correlacionar métodos de análise a fim de avaliar a disponibilidade de fósforo e potássio no solo para as plantas em experimentos com sistema plantio direto conduzidos no Estado do Rio Grande do Sul.

\section{MATERIAL E MÉTODOS}

Os experimentos utilizados neste estudo foram conduzidos por diferentes instituições, em vários solos, com diferentes épocas de cultivo, tempo de condução, delineamento experimental e tratamentos. Foram utilizados os experimentos onde foi possível obterem-se as amostras de solo dos tratamentos com doses crescentes de fósforo e potássio. A descrição dos tratamentos, os locais de condução, o tipo de solo, o ano de condução e as culturas utilizadas para os experimentos com doses de $\mathrm{P}$ e com doses de K são mostrados nas tabelas 1 e 2 , respectivamente.
O fósforo e o potássio foram extraídos pelos métodos Mehlich-1 e resina, descritos em TEDESCO et al. (1995), e pelo método Mehlich-3, descrito em SCHLINDWIEN \& GIANELLO (2008). Todos os procedimentos foram feitos em duplicata de laboratório, e foram utilizados os valores médios. Foi feita a relação entre as quantidades extraídas pelos métodos e foi verificado o grau de associação entre as variáveis por meio da análise de correlação linear de Pearson. Foram determinadas as quantidades mínima, máxima e média de fósforo extraído pelos métodos.

\section{RESULTADOS E DISCUSSÃO}

A solução de Mehlich-1 extraiu as menores quantidades médias e medianas de fósforo em relação ao método da resina, e as quantidades de fósforo extraído pelo método da resina foram menores do que as quantidades de fósforo extraído pela solução de Mehlich-3 (Tabela 3). Esse comportamento também foi observado por MEHLICH(1984), SIMS (1989), BRASIL \& MARUOKA(1997), MIOLA et al. (1999), SILVA \& RAIJ (1999), GARTLEY et al. (2002), MALLARINO \& ATIA (2005), RING et al. (2005), ALCÂNTARA et al. (2008), BORTOLON \& GIANELLO (2008), SCHLINDWEIN \& GIANELLO (2008) e SILVA et al. (2008). Essa tendência se manteve nas duas profundidades de amostragem. Em média, os teores de fósforo extraídos pela solução de Mehlich-1 foram $12,7 \%$ maiores na camada de $0-10 \mathrm{~cm}$ (Tabela 1 ). SCHLINDWEIN \& ANGHINONI (2000) encontraram teores de fósforo $50 \%$ maiores na camada de $0-10 \mathrm{~cm}$ em experimentos de longa duração cultivados no sistema plantio direto. O menor valor dos teores de fósforo na camada de $0-10 \mathrm{~cm}$, obtido neste trabalho em relação aos obtidos por SCHLINDWEIN \& ANGHINONI (2000) está associado ao menor tempo de adoção do sistema plantio direto nas áreas utilizadas neste trabalho. O tempo de adoção do sistema plantio direto propicia o acúmulo de fósforo em superfície devido à baixa mobilidade no solo (SCHLINDWEIN \& ANGHINONI, 2000; MALLARINO, \& ATIA, 2005; RHEINHEIMER et al., 2008; SCHLINDWEIN \& GIANELLO, 2008).

As quantidades médias e medianas de fósforo (Mehlich-1 < resina < Mehlich-3) não seguiram o comportamento para as extrações mínimas e máximas dos três métodos. Isso pode ser devido aos diferentes mecanismos de extração dos métodos. Resultados adaptados de BORTOLON \& GIANELLO (2006) mostram que, em solos argilosos, o método da resina extrai mais fósforo que em solos arenosos, e a extração é ainda maior em solos com altos teores de fósforo, 
Tabela 1 - Doses aplicadas de $\mathrm{P}_{2} \mathrm{O}_{5}$ nos experimentos em diferentes instituições, locais, solos, anos de cultivo e culturas cultivadas.

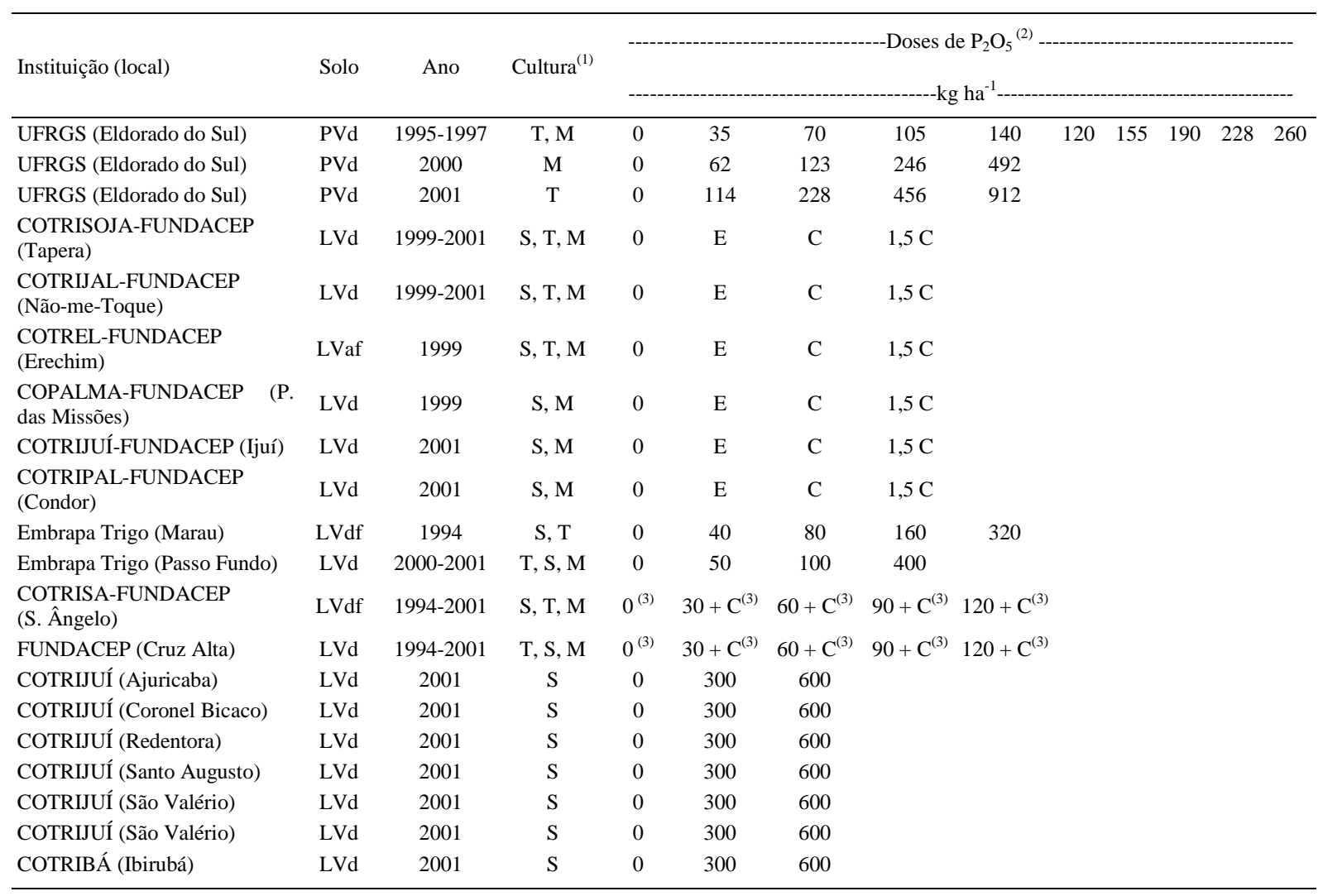

(1) As culturas são: S: soja, T: trigo M: milho e P: pastagem; ${ }^{(2)}$ - As doses de adubação são: E: quantidade exportada de $\mathrm{P}_{2} \mathrm{O}_{5}$ e C: dose recomendada de $\mathrm{P}_{2} \mathrm{O}_{5}$ pela Comissão... (1995) ; ${ }^{(3)}$ - Adubação de 0 , 30, 60, 90 e $120 \mathrm{~kg}$ ha ${ }^{-1}$ de $\mathrm{P}_{2} \mathrm{O}_{5}$ nas culturas de inverno, nas parcelas principais, e 0 , $1 / 3$, 2/3, $3 / 3$ e 4/3 da dose recomendada pela Comissão... (1995) para cada cultura de verão nas sub-parcelas.

como também observado por BISSANI et al. (2002) e SCHLINDWEIN (2003). A solução de Mehlich-1 extrai o fósforo por dissolução seletiva das frações mais lábeis em função da redução do pH. Em solos mais argilosos, com alto poder tampão, o tempo de decantação de 16 horas utilizado na metodologia de extração (TEDESCO et al., 1995) pode propiciar o desgaste da capacidade de extração e ocorrer readsorção de fósforo já dissolvido, resultando em valores de fósforo extraído menores nos solos argilosos em comparação aos solos arenosos (BEEGLE, 2005). Esse efeito é reduzido com o método da resina ao extrair o fósforo da solução do solo por mecanismo de troca iônica entre o bicarbonato adsorvido na resina, o qual, por gradiente de concentração, vai para a solução, e o fosfato ocupa o sítio de adsorção na resina para manter o equilíbrio químico. Com a redução do fósforo da solução do solo, há a reposição por fósforo oriundo de formas adsorvidas até a exaustão das fontes consideradas disponíveis (lábeis), que podem passar para a solução durante o período de extração favorecido pela saturação com água e a agitação de 16 horas. A agitação favorece a extração do fósforo do solo devido à presença do dreno, que é a resina. $\mathrm{O}$ fósforo ligado à resina não está em equilíbrio com a solução, tal como ocorre no processo de extração do método Mehlich-1. Assim, em solos com maior poder tampão de fósforo, como os argilosos, a extração de fósforo é maior no método da resina do que no método Mehlich-1. Isso não necessariamente ocorre em solos arenosos. Por outro lado, na extração com solução ácida, há a dissolução dessas formas pela ação dos íons presentes na composição da solução extratora. No entanto, nesse processo pode ocorrer a dissolução de compostos estáveis de fósforo no solo que não contribuem para o fósforo da solução, principalmente, os fosfatos de cálcio (RAIJ et al., 1986). Além disso, pode ocorrer a neutralização ou complexação de componentes da solução extratora por compostos orgânicos e inorgânicos presentes no solo, reduzindo a eficiência da extração.

A maior quantidade de fósforo extraído com a solução de Mehlich-3 deve-se, em parte, às características químicas do extrator, que extrai preferencialmente o fósforo ligado ao ferro e ao alumínio 
Tabela 2 - Doses de $\mathrm{K}_{2} \mathrm{O}$ aplicadas nos experimentos em diferentes instituições, locais, solos, anos de cultivo e culturas cultivadas.

\begin{tabular}{|c|c|c|c|c|c|c|c|c|}
\hline \multirow{3}{*}{$\begin{array}{l}\text { Instituição (local) } \\
\text { UFRGS (Eldorado do Sul) }\end{array}$} & \multirow{3}{*}{$\begin{array}{l}\text { Solo } \\
\text { PVd }\end{array}$} & \multirow{3}{*}{$\begin{array}{c}\text { Ano } \\
2000\end{array}$} & \multirow{3}{*}{$\begin{array}{c}\text { Cultura }^{(1)} \\
\mathrm{M}\end{array}$} & \multirow{2}{*}{\multicolumn{5}{|c|}{ 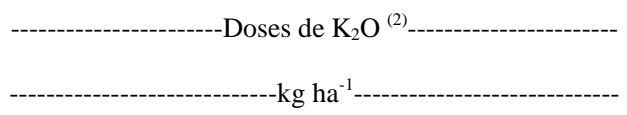 }} \\
\hline & & & & & & & & \\
\hline & & & & 0 & 12 & 23 & 46 & 93 \\
\hline UFRGS (Eldorado do Sul) & PVd & 2001 & $\mathrm{~T}$ & 0 & 23 & 46 & 93 & 186 \\
\hline COTRISOJA-FUNDACEP (Tapera) & LVd & 1999-2001 & $\mathrm{S}, \mathrm{T}, \mathrm{M}$ & 0 & $\mathrm{E}$ & $\mathrm{C}$ & $1,5 \mathrm{C}$ & \\
\hline COTRIJAL-FUNDACEP (Não-me-Toque) & LVd & 1999-2001 & S, T, M & 0 & $\mathrm{E}$ & $\mathrm{C}$ & $1,5 \mathrm{C}$ & \\
\hline COTREL-FUNDACEP (Erechim) & LVaf & 1999 & $\mathrm{~S}, \mathrm{~T}, \mathrm{M}$ & 0 & $\mathrm{E}$ & $\mathrm{C}$ & $1,5 \mathrm{C}$ & \\
\hline COPALMA-FUNDACEP (P. das Missões) & LVd & 1999 & S, M & 0 & $\mathrm{E}$ & $\mathrm{C}$ & $1,5 \mathrm{C}$ & \\
\hline COTRIJUÍ-FUNDACEP (Ijuí) & LVd & 2001 & S, M & 0 & $\mathrm{E}$ & $\mathrm{C}$ & $1,5 \mathrm{C}$ & \\
\hline COTRIPAL-FUNDACEP (Condor) & LVd & 2001 & $\mathrm{~S}, \mathrm{M}$ & 0 & $\mathrm{E}$ & $\mathrm{C}$ & $1,5 \mathrm{C}$ & \\
\hline UFSM (São Francisco de Assis) & RQ & $1995-1998$ & $\mathrm{~S}, \mathrm{M}, \mathrm{P}$ & 0 & 50 & 100 & 200 & \\
\hline COTRISA-FUNDACEP (Santo Ângelo) & LVdf & $1994-2001$ & $\mathrm{~S}, \mathrm{M}, \mathrm{T}$ & $0^{(3)}$ & $30+C^{(3)}$ & $60+C^{(3)}$ & $90+C^{(3)}$ & $120+C^{(3)}$ \\
\hline FUNDACEP (Cruz Alta) & LVd & 1994-2001 & $\mathrm{S}, \mathrm{M}, \mathrm{T}$ & $0^{(3)}$ & $30+C^{(3)}$ & $60+C^{(3)}$ & $90+C^{(3)}$ & $120+C^{(3)}$ \\
\hline COTRIJUÍ (Ajuricaba) & LVd & 2001 & $\mathrm{~S}$ & 0 & 300 & 600 & & \\
\hline COTRIJUÍ (Coronel Bicaco) & LVd & 2001 & $\mathrm{~S}$ & 0 & 300 & 600 & & \\
\hline COTRIJUÍ (Redentora) & LVd & 2001 & $\mathrm{~S}$ & 0 & 300 & 600 & & \\
\hline COTRIJUÍ (Santo Augusto) & LVd & 2001 & $\mathrm{~S}$ & 0 & 300 & 600 & & \\
\hline COTRIJUÍ (São Valério) & LVd & 2001 & $\mathrm{~S}$ & 0 & 300 & 600 & & \\
\hline COTRIJUÍ (São Valério) & LVd & 2001 & $\mathrm{~S}$ & 0 & 300 & 600 & & \\
\hline COTRIBÁ (Ibirubá) & LVd & 2001 & $\mathrm{~S}$ & 0 & 300 & 600 & & \\
\hline
\end{tabular}

(1) As culturas são: S: soja, T: trigo M: milho e P: pastagem ; ${ }^{(2)}$ - As doses de adubação são: E: quantidade exportada de $\mathrm{K}_{2} \mathrm{O}$ e C: dose recomendada de $\mathrm{K}_{2} \mathrm{O}$ pela Comissão... (1995) ; ${ }^{(3)}$ - Adubação de - 0, 30, 60, 90 e $120 \mathrm{~kg} \mathrm{ha}^{-1}$ de $\mathrm{K}_{2} \mathrm{O}$ nas culturas de inverno, nas parcelas principais, e 0,1/3, 2/3, 3/3 e 4/3 da dose recomendada pela Comissão... (1995) para cada cultura de verão nas sub-parcelas.

(elementos presentes em grandes quantidades nos solos estudados) e, em menor quantidade, o fósforo ligado ao cálcio (BEEGLE, 2005). As maiores quantidades de fósforo extraído possibilitam classes de fertilidade mais amplas e reduzem o erro nas recomendações de adubação, reduzindo, ainda, o erro analítico. Os coeficientes de correlação obtidos entre as quantidades de fósforo extraído pelos métodos são mostrados na figura 1. O maior valor observado foi entre a solução de Mehlich-1 e de Mehlich-3 (0,94**)

Tabela 3 - Quantidades mínima, máxima, média e mediana de fósforo e de potássio extraídos do solo por diferentes métodos, em duas profundidades de amostragem, em solos com adubação fosfatada e potássica sob sistema plantio direto.

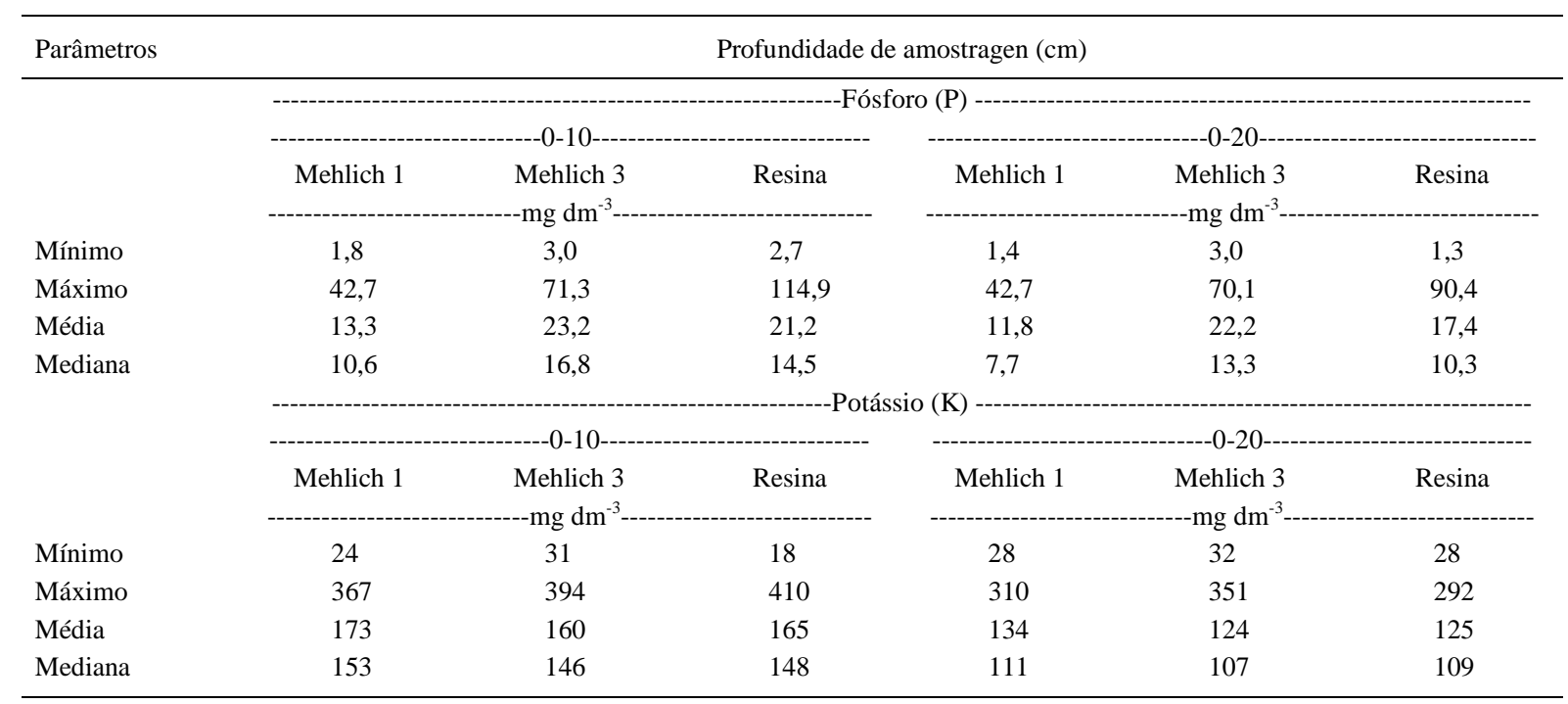

Ciência Rural, v.39, n.8, nov, 2009. 


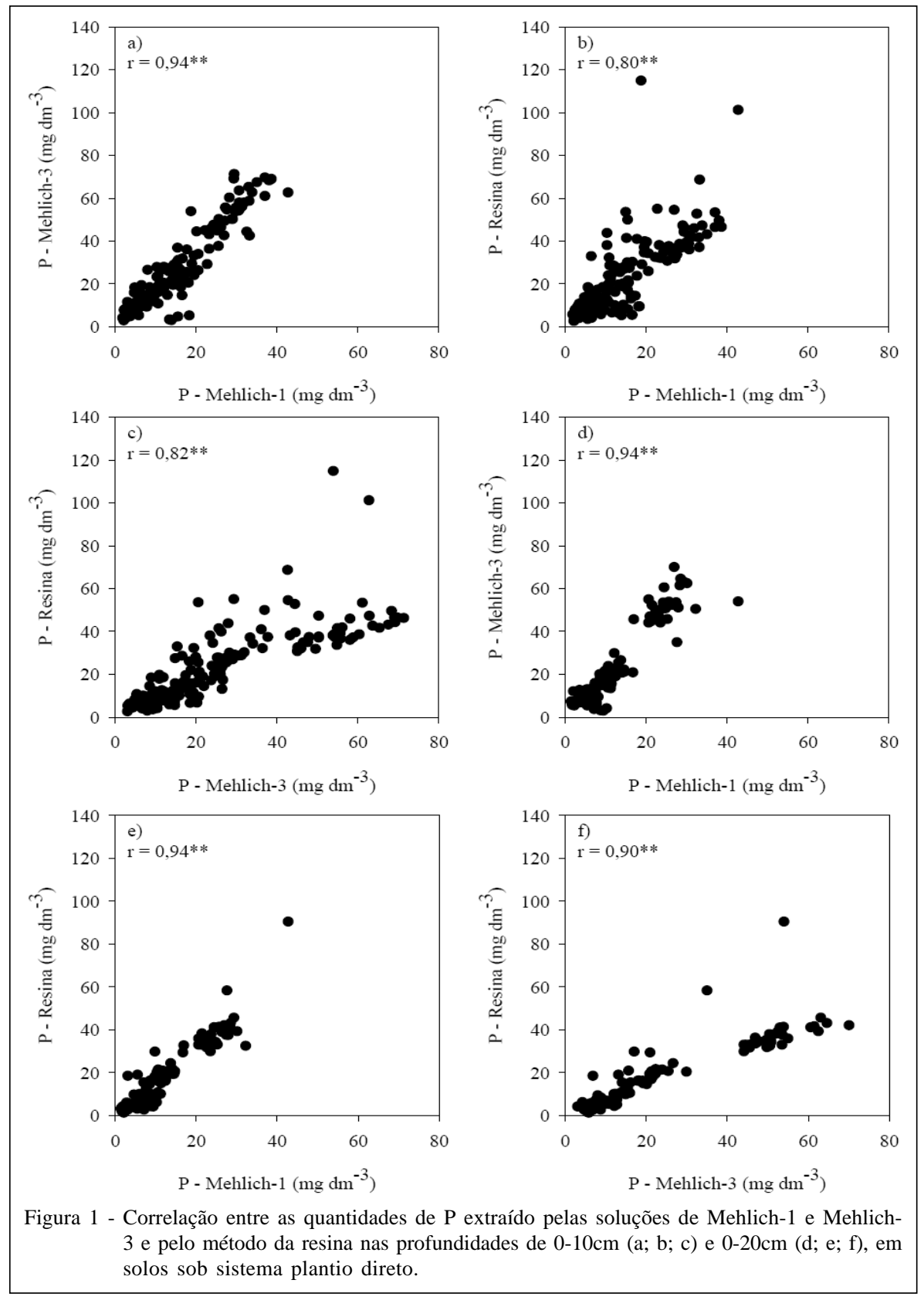

na profundidade de $0-10 \mathrm{~cm}$. Isso ocorre porque os métodos atuam sobre formas de $\mathrm{P}$ no solo semelhantes, diferentemente do método da resina.

As quantidades de potássio extraído pelos métodos (Tabela 1) tiveram valores proporcionalmente mais semelhantes entre si do que entre os de fósforo. Isso pode ser explicado pelo fato de as metodologias acessarem formas similares de potássio no solo. A solução de Mehlich-1 extraiu maiores quantidades médias e medianas de potássio em relação ao método da resina e ambos maiores do que a solução de Mehlich-
3, como também observado por MEHLICH (1984), SIMS (1989), MAMO et al. (1996) e SCHLINDWEIN (2003). Essa tendência se manteve nas duas profundidades de amostragem, sendo maior em 29,1\% para o potássio extraído pela solução de Mehlich-1 na camada de 0$10 \mathrm{~cm}$, em relação à camada de $0-20 \mathrm{~cm}$. Essa tendência era esperada, pois a mesma dose do fertilizante potássico, que é menos reativo e mais móvel no solo, é diluída no dobro de solo nas amostras de $0-20 \mathrm{~cm}$ em relação a de $0-10 \mathrm{~cm}$. Além disso, grande parte do potássio absorvido pelas plantas e remanescente nos 
resíduos retorna ao solo após o cultivo, conforme demonstrado por GIACOMINI et al. (2003) em diversas espécies de plantas de coberturas cultivadas em sistema plantio direto, os quais observaram que independentemente da espécie, após 30 dias de manejo das plantas, aproximadamente $75 \%$ do potássio acumulado retorna ao solo. Esse comportamento favorece o acúmulo de potássio nas camadas superficiais do solo. SCHLINDWEIN \& ANGHINONI
(2000) encontraram teores de potássio 30\% maiores na camada de $0-10 \mathrm{~cm}$, em experimentos de longa duração cultivados no sistema plantio direto.

A correlação entre as variáveis apresentou um alto grau de associação e significância, para ambas as profundidades de amostragem (Figura 2), o que indica que qualquer uma das metodologias estudadas pode ser utilizada para avaliação da disponibilidade de potássio para as plantas em solos sob plantio direto.

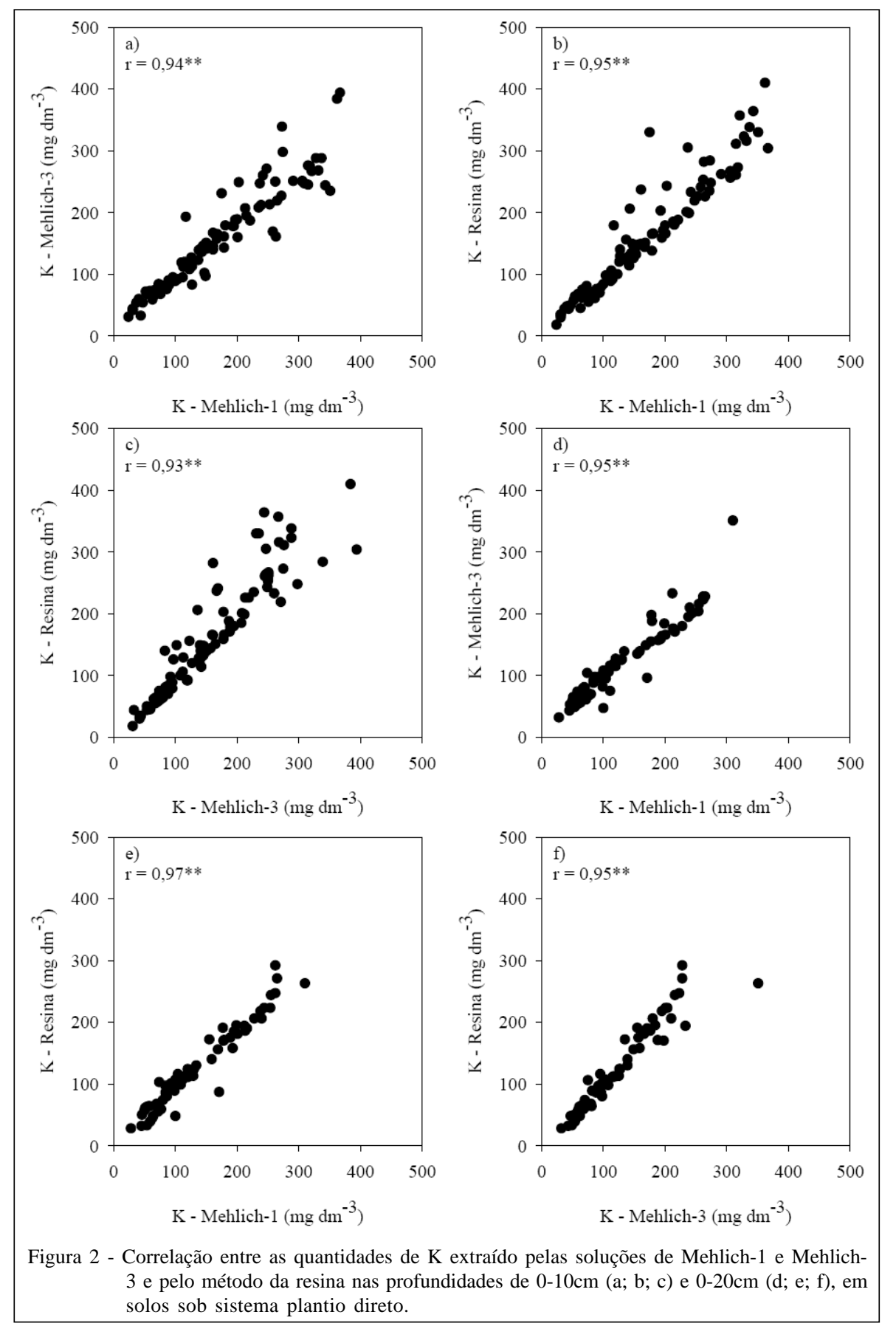

Ciência Rural, v.39, n.8, nov, 2009. 


\section{CONCLUSÃO}

Com base nos resultados obtidos, pode-se concluir que as três metodologias estudadas são eficientes na extração de fósforo e potássio no solo em sistema plantio direto. Porém, devido às maiores quantidades de $\mathrm{P}$ extraído pelos métodos da resina e da solução de Mehlich-3, os erros em laboratório podem ser menores do que os obtidos com o método Mehlich1, pela maior amplitude de extração desses métodos, tendo classes de fertilidade mais amplas.

\section{AGRADECIMENTOS}

Os autores agradecem as seguintes instituições que conduziram experimentos e gentilmente cederam os dados: UFSM, EMBRAPA Trigo, FUNDACEP e FUNDACEP (verificar), em convênio com cooperativas COTRISOJA, COTRIJAL, COTREL, COPALMA, COTRIJUI, COTRIPAL, COTRISA e COTRIBÁ. Ao Conselho Nacional de Desenvolvimento Científico e Tecnológico (CNPq), pela concessão de bolsa de doutorado ao primeiro autor.

\section{REFERÊNCIAS}

ALCÂNTARA, F.A. e t al. Extraction methods for phosphorus and their relationship with soils phosphorus-buffer capacity estimated by the remaining-phosphorus methodology-a pot study with maize. Communications in Soil Science and Plant Analysis, New York, v39, n.3\&4, p.603-615, 2008.

ANGHINONI, I. Fertilidade do solo e seu manejo em sistema plantio direto. In: NOVAIS, R.F. et al. (ed). Fertilidade do solo. Viçosa: SBCS, 2007. p.873-928.

BEEGLE, D. Assessing soil phosphorus for crop production by soil testing. In: SIMS, J.T. et al. (Ed.). Phosphorus: agriculture and the environment. Madison: SSSA, 2005. p.123-144.

BISSANI, C.A. et al. Anion-exchange resins and iron oxideimpregnated filter paper as plant available phosphorus indicators in soils. Communications in Soil Science and Plant Analysis, New York, v.33, p.1119-1129, 2002.

BORTOLON, L.; GIANELLO, C. Phosphorus availability to maize determined by several methods on Rio Grande do Sul (Brazil) soils. In: INTERNATIONAL SYMPOSIUM PHOSPHORUS DYNAMICS IN SOIL-PLANT CONTINUUM, 3., 2006, Uberlândia, MG. Anais... Uberlândia: Embrapa., 2006. p.49-52.

BORTOLON, L.; GIANELLO, C. Interpretação de resultados analíticos de fósforo pelos extratores Mehlich-1 e Mehlich-3 em solos do Rio Grande do Sul. Revista Brasileira de Ciência do Solo, Viçosa, v.32, p.1369-1377, 2008. Disponível em: < http://www.scielo.br/scielo.php? script=sci_arttext\&pid=S0100$06832008000700019 \& \operatorname{lng}=p t \& n r m=i s o \& t \operatorname{lng}=p t>$. Acesso em: 11 Maio 2009. doi: 10.1590/S0100-06832008000700019.

BRASIL, E.C.; MURAOKA, T. Extratores de fósforo em solos da Amazônia tratados com fertilizantes fosfatados. Revista
Brasileira de Ciência do Solo, Campinas, v.21, n.3, p.599606, 1997.

GARTLEY, K.L. et al. Comparison of soil test extractants used in Mid-Atlantic United States. Communication in soil Science of Plant Analysis, New York, v.33, p.873-895, 2002.

MALLARINO, A.P.; ATIA, A.M. Correlation of a resin membrane soil phosphorus test with corn yield and routine soil tests. Soil Science Society of American Journal, Madison, v.69, p.266-272. 2005.

GIACOMINI, S.J. et al. Liberação de fósforo e potássio durante a decomposição dos resíduos culturais de plantas de cobertura em plantio direto. Pesquisa Agropecuária Brasileira, Brasília, v.38, p.1097-1104, 2003. Disponível em: <http://www.scielo.br/ s cielo.php? s c ri p t = s ci_art text \& pi d = S 0100 204X2003000900011\&lng=pt\&nrm=iso\&tlng=pt>. Acesso em: 11 Maio 2009. doi: 10.1590/S0100-204X2003000900011.

MAMO, T. et al. Comparision of extractants for the determination of available phosphorus, potassium, calcium, magnesium and sodium in some Ethiopian and German soils. Communication in soil Science of Plant Analysis, New York, v.27, p.2197-2212, 1996.

MEHLICH, A. Mehlich 3 soil test extractant: A modification of Mehlich 2 extractant. Communications in Soil Science and Plant Analysis, New York, v.15, p.1409-1416, 1984.

MIOLA, G.R. et al. Avaliação da disponibilidade de fósforo para a cultura do milho. Pesquisa Agropecuária Brasileira, Brasília, v.34, n.5, p.813-819, 1999. Disponível em: < http:// www.scielo.br/scielo.php?script=sci_arttext\&pid=S0100204X1999000500012\&lng=pt\&nrm=iso\&tlng=pt $>$. Acesso em: 11 Maio 2009. doi: 10.1590/S0100-204X1999000500012.

RAIJ, B. van et al. Extraction of phosphorus, potassium, calcium and magnesium from soil by an ion-exchange resin procedure. Communication in soil Science of Plant Analysis, New York, v.17, p.547-566, 1986.

RHEINHEIMER, D.S. et al. Fatores que afetam a disponibilidade do fósforo e o manejo da adubação fosfatada em solos sob sistema plantio direto. Ciência Rural, Santa Maria, v.38, p.576-586, 2008. Disponível em: < http://www.scielo.br/ s cielo.php? script=s ci_art text \& pid = S 0103 $84782008000200049 \& \operatorname{lng}=\mathrm{pt} \& \mathrm{nrm}=\mathrm{iso} \& \operatorname{lng}=\mathrm{pt}>$. Acesso em: 11 Maio 2009. doi: 10.1590/S0103-84782008000200049.

RING, R.A. et al. Determining available soil phosphorus in nova scotia blueberry soils. Communications in Soil Science and Plant Analisys, New York, v.35, n.17\&18, p.2449-2463, 2005.

SCHLINDWEIN, J.A.; GIANELLO, C. Calibração de métodos de determinação de fósforo em solos cultivados sob sistema plantio direto. Revista Brasileira de Ciência do Solo, Viçosa, v.32, p.2037-2049, 2008. Disponível em: < http:// www.scielo.br/scielo.php?script=sci_arttext\&pid=S0100$06832008000500025 \& \operatorname{lng}=p t \& n r m=i s o \& t \operatorname{lng}=p t>$. Acesso em: 11 Maio 2009. doi: 10.1590/S0100-06832008000500025.

SCHLINDWEIN, J.A.; ANGHINONI, I. Variabilidade vertical de fósforo e potássio disponíveis e profundidade de amostragem 
do solo no sistema plantio direto. Ciência Rural, Santa Maria, v.30, p.611-617, 2000. Disponível em: < http://www.scielo.br/ scielo.php? script = s ci_art text \& pid = S 0103 $84782000000400009 \& \operatorname{lng}=\mathrm{pt} \& \mathrm{nrm}=\mathrm{iso} \& \mathrm{t} \operatorname{lng}=\mathrm{pt}>$. Acesso em: 11 Maio 2009. doi: 10.1590/S0103-84782000000400009.

SILVA, F.C.; RAIJ, B.V. Disponibilidade de fósforo em solos avaliada por diferentes extratores. Pesquisa Agropecuária Brasileira, Brasilia, v.34, n.2, p.267-288, 1999. Disponível em: <http:// www.scielo.br/scielo.php?script $=$ sci_arttext \&pid=S0100 204X1999000200016\&lng=pt\&nrm=iso $>$. Acesso em: 11 Maio 2009. doi: 10.1590/S0100-204X1999000200016.

SILVA, L.S. et al. Avaliação de métodos para estimativa da disponibilidade de fósforo para arroz em solos de várzea do Rio
Grande do Sul. Revista Brasileira de Ciência do Solo, Vicosa, v.32, p.207-216, 2008. Disponível em <http:// www.scielo.br/scielo.php?script $=$ sci_arttext \&pid $=$ S010006832008000100020\&lng=pt\&nrm=iso $>$. Acesso em: 11 maio 2009. doi: 10.1590/S0100-06832008000100020.

SIMS, J.T. Comparison of Mehlich 1 and Mehlich 3 extractants for $\mathrm{P}, \mathrm{K}, \mathrm{Ca}, \mathrm{Mg}, \mathrm{Mn}, \mathrm{Cu}$ and $\mathrm{Zn}$ in Atlantic coastal plain soils. Communications in Soil Science and Plant Analysis, New York, v.20, p.1707-1726. 1989

TEDESCO, M.J. et al. Análise de solo, plantas e outros materiais. 2.ed. Porto Alegre: Departamento de Solos da UFRGS, 1995. 147p. (Boletim Técnico, 5). 